\title{
Análise dos processos de gestão do conhecimento no departamento comercial de empresa do setor de telecomunicações de Santa Catarina
}

\author{
Liana Souza da Rosa ${ }^{1}$ \\ Marcos Baptista Lopes Dalmau ${ }^{2}$ \\ Alessandra de Linhares Jacobsen ${ }^{3}$
}

\section{Resumo}

O principal objetivo deste trabalho foi analisar os processos de gestão do conhecimento aplicados no departamento comercial de empresa do setor de telecomunicações de Santa Catarina. Partindo dessa perspectiva, foram estudadas as teorias relacionadas aos processos da gestão do conhecimento, no que tange à geração, ao compartilhamento, à armazenagem e ao mapeamento dos conhecimentos. Referente à metodologia, desenvolveu-se um estudo quantitativo, qualitativo, descritivo, e estudo de caso. Os dados primários foram obtidos através de questionários aplicados aos colaboradores do departamento comercial e de entrevistas semiestruturadas realizadas com Diretor comercial, Gerente, Coordenador e Supervisora. Os dados secundários decorrem de levantamento bibliográfico. Identificou-se que os processos de geração de conhecimentos são diferenciados em cada setor do departamento, os processos de armazenagens desses conhecimentos não são totalmente eficazes visto que nem todos os conhecimentos são registrados pelos colaboradores. O compartilhamento dos conhecimentos é realizado mediante realização de reuniões, e-mails e informativos, porém, nem todos os conhecimentos são compartilhados entre os colaboradores do mesmo grupo de trabalho e com os demais colaboradores da empresa. Ainda é importante destacar que não existe um mapeamento formalizado de conhecimentos e competências dos indivíduos, suas tarefas e responsabilidades.

Palavras-chave: Gestão do Conhecimento. Informação. Telecomunicações.

\footnotetext{
${ }^{1}$ Bacharel em Administração pela Universidade Federal de Santa Catarina. Endereço: Universidade Federal de Santa Catarina, Centro SócioEconômico, Departamento de Ciências da Administração. Campus Universitário Trindade, Florianopolis, SC. CEP: 88040-900. E-mail: liana.souza@gmail.com.

${ }^{2}$ Doutor em Engenharia de Produção pela Universidade Federal de Santa Catarina. Professor do Departamento de Ciências da Administração e Coordenador do Curso de Graduação em Administração da Universidade Federal de Santa Catarina. Endereço: Universidade Federal de Santa Catarina, Centro Sócio-Econômico, Departamento de Ciências da Administração. Campus Universitário Trindade, Florianopolis, SC. CEP: 88040-900. E-mail: dalmau@cse.ufsc.br.

${ }^{3}$ Doutora em Engenharia de Produção pela Universidade Federal de Santa Catarina. Professora do Departamento de Ciências da Administração da Universidade Federal de Santa Catarina. Endereço: Universidade Federal de Santa Catarina, Centro Sócio-Econômico, Departamento de Ciências da Administração. Campus Universitário Trindade, Florianópolis, SC. Caixa-Postal: 476. CEP: 88040-900. E-mail: oajac@newsite.com.br. Artigo recebido em: 04/04/2008. Aceito em: 03/09/2008. Membro do Corpo Editorial Científico responsável pelo processo editorial: Emerson Antônio Maccari.
} 


\section{Introdução}

Nos últimos anos as organizações enfrentaram um período de mudança em vários aspectos econômicos e sociais que resultaram em sua reestruturação, sendo que a revolução do conhecimento tornou este em um grande diferencial competitivo para as organizações globalizadas. Dessa forma, o conhecimento está sendo criado e recriado intensamente nas empresas; ou seja, está em constante transformação.

Após assimilar esta nova concepção, as organizações concluíram um ciclo de gestão baseado na produtividade, para iniciar um novo período baseado no conhecimento. $\mathrm{O}$ grande interesse que demonstram as empresas pelo conhecimento acentua-se a partir da constatação de que, por exemplo, o valor de mercado (ação) de algumas empresas chega a ser muito maior do que o valor do patrimônio financeiro e físico que possuem; ocorre esta diferenciação porque no mercado as ações incorporam valores ditos intangíveis, tais como: a marca, a forma como a empresa se apresenta no mercado e perante seus consumidores e concorrentes, a capacidade da organização de desenvolver produtos inovadores com frequência e a competência apresentada por seus colaboradores (TONET; PAZ, 2004, p. 2).

Portanto, para que qualquer organização possa ampliar a sua competitividade, a sua qualidade e a sua eficácia percebida nos dias atuais, é essencial que as empresas se utilizem da inteligência e do conhecimento de cada um dos seus colaboradores. Este gerenciamento deve objetivar a criação do conhecimento, assim como as formas de compartilhá-lo, e deve respeitar pontos específicos da organização, tais como: cultura, clima organizacional, disponibilidade de recursos humanos, dentre outros.

A empresa analisada realiza este aprimoramento através da utilização de tecnologia de ponta no desenvolvimento das soluções ofertadas. Caracteriza-se como uma empresa voltada para o conhecimento, pois cultiva o aprimoramento e o desenvolvimento profissional de seus colaboradores, reconhecendo-os como recursos estratégicos e principal fonte de sua vantagem competitiva perante o mercado.

O mercado de Telecomunicações, no qual a organização está inserida, é altamente dinâmico e competitivo. As transformações nesse mercado iniciaram-se após a privatização do Sistema Telebrás (Telecomunicações Brasileiras S. A.) em 1998. 
Nos anos seguintes a essa privatização, ocorreu uma abertura de mercado, possibilitando que diversas organizações concluíssem o desenvolvimento de soluções variadas e inovadoras. Apostando neste novo nicho de mercado e acreditando em seu crescimento, a empresa em análise realizou o lançamento de produtos, os quais, com o passar do tempo, foram aprimorados com o auxílio de seus colaboradores.

Visando manter a característica de lançamento de produtos inovadores, é de essencial importância que a empresa e seus colaboradores busquem o desenvolvimento tecnológico através de desenvolvimento e internalização de novos conhecimentos. Ainda é importante ressaltar que tanto as informações e os conhecimentos absorvidos pela organização no mercado em que atua quanto o desenvolvimento e a criação de novos conceitos podem facilitar a alta administração da empresa no processo de tomada de decisão.

O departamento comercial da empresa está subdividido em cinco setores específicos que atuam com responsabilidades e conhecimentos diferenciados. A organização possui visão acentuada de hierarquia, pois todas as decisões ocorrem de cima para baixo, sendo apenas comunicadas e aceitas pelos demais colaboradores. Entretanto, essas decisões são formuladas a partir das informações organizadas e constituídas a partir do conhecimento e experiências dos colaboradores.

As decisões realizadas pelo departamento comercial trazem definições tanto de cunho estratégico quanto operacionais, pois definem a formulação $e$ a adoção de preços dos produtos ofertados pela organização, procedimentos operacionais para elaboração de propostas destinadas aos clientes, e análise financeira através das taxas internas de retorno ou margens de contribuição.

Para realizar todas essas atividades, é essencial que o colaborador possua um conhecimento abrangente de administração das rotinas operacionais, estratégias e finanças. Sendo assim, é necessário que a organização possua uma gestão desses conhecimentos para que eles não se percam no caso de ausência ou desligamento (demissão) do colaborador, garantindo, assim, que a organização permanecerá obtendo segurança nas informações destinadas à cúpula estratégica do departamento comercial, seja na realização do processo de definição, seja na realização das atividades diárias.

O objetivo geral deste estudo é identificar quais ações voltadas para a gestão do conhecimento deverão ser desenvolvidas para o departamento comercial dessa empresa do setor de telecomunicações de Santa Catarina para proporcionar novos subsídios para o desenvolvimento de suas atividades. 


\section{Metodologia}

Para realização da pesquisa apresentada, optou-se pela utilização de pesquisa de natureza qualitativa e quantitativa. A análise qualitativa possibilita a descrição com maior número de detalhes dos processos relacionados à gestão do conhecimento. A aplicação dessa análise objetivou a interpretação do conteúdo das entrevistas, dos questionários e das observações, de modo a resultar em uma análise real, sem manipulações de resultados.

Já o método quantitativo foi utilizado na caracterização dos trabalhadores ligados às áreas do conhecimento e alocados no departamento analisado, na realização das análises das respostas apresentadas pelos colaboradores do Departamento Comercial quando da aplicação dos questionários, e na realização de análises gráficas das demais respostas deste instrumento de coleta de dados.

A pesquisa apresenta, ainda, caráter exploratório, uma vez que não existia qualquer avaliação preliminar ou material elaborado com análise dos processos de gestão do conhecimento realizados nessa empresa. Mostra-se, também, com qualidades de pesquisa descritiva no que tange ao relato de métodos e procedimentos em uso pela referida empresa para posterior análise dos processos de gestão do conhecimento. A descrição de tais processos tornou-se viável com a utilização dos métodos de observação, aplicação de questionários e a realização de entrevistas semiestruturadas. Já a pesquisa bibliográfica utilizada neste trabalho deu o respaldo necessário para a fundamentação teórica desta análise.

O universo desta pesquisa foi o número total de funcionários alocados no Departamento Comercial dessa organização. Esses trabalhadores estão alocados em cinco setores com responsabilidades específicas. Desta forma, pode-se afirmar que a delimitação da amostra seguiu o método nãoprobabilístico, visto que se trata de método menos rigoroso, permitindo que o pesquisador selecione os elementos a serem pesquisados mediante a acessibilidade e representatividade destes para o estudo.

Quanto à forma de aplicação desta pesquisa, as ferramentas utilizadas para a coleta de dados primários foram: entrevistas semiestruturadas realizadas com Diretor, Gerente, Coordenação e Supervisora; questionários, com perguntas fechadas, aplicados aos demais colaboradores do departamento comercial; e, ainda, observação participante. Já a coleta de dados secundári- 
Análise dos processos de gestão do conhecimento no departamento comercial de empresa do setor de telecomunicações...

os foi realizada através de levantamentos bibliográficos. Importante salientar que no decorrer desta pesquisa não se utilizou análise documental.

\section{Fundamentação Teórica}

$\mathrm{O}$ ato de criar, reter e utilizar os conhecimentos disponibilizados pelas organizações passa a ser item básico para enfrentar mudanças constantemente impostas pelos atuais mercados em que as empresas estão inseridas. Para tal, torna-se essencial compreender a definição exata de todas as partes integrantes dos fluxos de informação. O fluxo inicia-se com a constatação de alguns dados que, após serem filtrados e analisados, transformam-se em informação. A informação, quando bem utilizada e armazenada pela empresa, transforma-se em conhecimento, que poderá ser um diferencial desta organização perante o mercado.

Os dados são as matérias-primas base para construção de uma informação. Segundo Davenport e Prusak (1998, p. 2) dados são como "um conjunto de fatos distintos e objetivos, relativos a eventos". Quer dizer, são todas as particularidades ou notícias expostas diariamente; sozinhos esses dados não traduzem conhecimento, porém, quando introduzidos em um contexto (encaixados em um quadro maior), resultam em grande conhecimento.

Para Angeloni (2003, p. 2) "a informação pode ser considerada como dados processados e contextualizados". Corroborando esta afirmação, Nonaka e Takeuchi (1997, p. 63) acreditam que "a informação proporciona um novo ponto de vista para a interpretação de eventos e objetos, o que torna visíveis significados antes de invisíveis ou lança luz sobre conexões inesperadas".

Já o conhecimento origina-se da informação. Davenport e Prusak (1998, p. 6) descrevem o conhecimento como:

[...] uma mistura fluida de experiência condensada, valores, informação contextual e insight experimentado, a qual proporciona uma estrutura para a avaliação e incorporação de novas experiências e informações.

O conhecimento é tudo aquilo que uma pessoa ou empresa sabe. Estas informações são provenientes de fontes internas e externas que podem ser reunidas durante dias, semanas ou anos. Segundo Rosenberg (2002, p. 61) 
Liana Souza da Rosa - Marcos Baptista Lopes Dalmau - Alessandra de Linhares Jacobsen

"o conhecimento pode ser caracterizado como explícito, tácito, individual e organizacional".

Na afirmação de Fleury e Oliveira Jr. (2001, p. 133)

[...] o conhecimento explícito refere-se ao conhecimento que é transmissível em linguagem formal, sistemática, enquanto o conhecimento tácito possui uma qualidade pessoal, o que o faz mais difícil de formalizar e comunicar.

Ao realizar análises do modelo de criação de conhecimento descrito por Nonaka e Takeuchi, identifica-se que o princípio da criação do conhecimento humano baseia-se na interação existente entre o conhecimento tácito e o conhecimento explícito, sendo que esse relacionamento ocorre de uma forma dinâmica e interativa.

Os conhecimentos dos indivíduos e das empresas, tácitos e explícitos, não estão isolados. Por esse motivo, o desempenho da empresa é resultado da combinação dos conhecimentos tácitos e explícitos dos indivíduos e das organizações, que formam a empresa (ROSENBERG, 2002). Pois, sob o ponto de vista de Fleury e Oliveira Jr. (2001, p. 133), "conhecimento organizacional é definido como o conjunto compartilhado de crenças sobre relações causais mantidas por indivíduos dento de um grupo".

As práticas que trabalham na empresa a concepção de gestão do conhecimento estão sendo amplamente difundidas e realizadas com sucesso pelas organizações no atual mercado em que atuam, e, em sua maioria, são implementadas com pioneirismo e espírito empreendedor pela empresas líderes de mercado e copiadas por empresas seguidoras.

\subsection{Gestão do Conhecimento}

Segundo Bueno et al. (2004, p. 4), gestão do conhecimento

é a estratégia que converte os bens intelectuais das organizações, tanto as informações como o talento dos membros, em maior produtividade, novo valor e aumento da competitividade.

Entretanto, o gerenciamento do conhecimento irá tornar-se ineficiente caso os colaboradores não localizem as informações importantes na organi- 
zação. Sendo assim, a primeira ação para realizar qualquer ação de gerenciamento é identificar quais as fontes ativas de informação na empresa, e, logo após, deve-se estudar formas viáveis para gerenciar as informações entrantes (ROSENBERG, 2002). Em complemento, Fleury e Oliveira Jr. (2001, p. 218) afirmam que

[...] o capital humano, formado pelos valores e normas individuais e organizacionais, bem como pelas competências, habilidades e atitudes de cada funcionário é a "mola propulsora' da geração do conhecimento e da geração de valor nas empresas.

A partir dessa afirmação, entende-se que é de essencial importância que as organizações reconheçam a necessidade de estimular o processo de inovação e compartilhamento das informações e de conhecimento, de forma a motivar os indivíduos na busca do desenvolvimento pessoal e profissional (FLEURY; OLIVEIRA Jr., 2001, p. 218).

Segundo Juliani (2002, p. 38) "os processos essenciais da gestão do conhecimento são definidos a partir da identificação de diversas atividades muito proximamente relacionadas". Assim, para realizar uma efetiva gestão do fluxo de informações e conhecimentos que circulam pela organização, é necessário que a empresa dispense especial atenção a esses processos, que são: identificação, aquisição, retenção, utilização, desenvolvimento e distribuição do conhecimento. Essa abordagem é exibida na Figura 1:

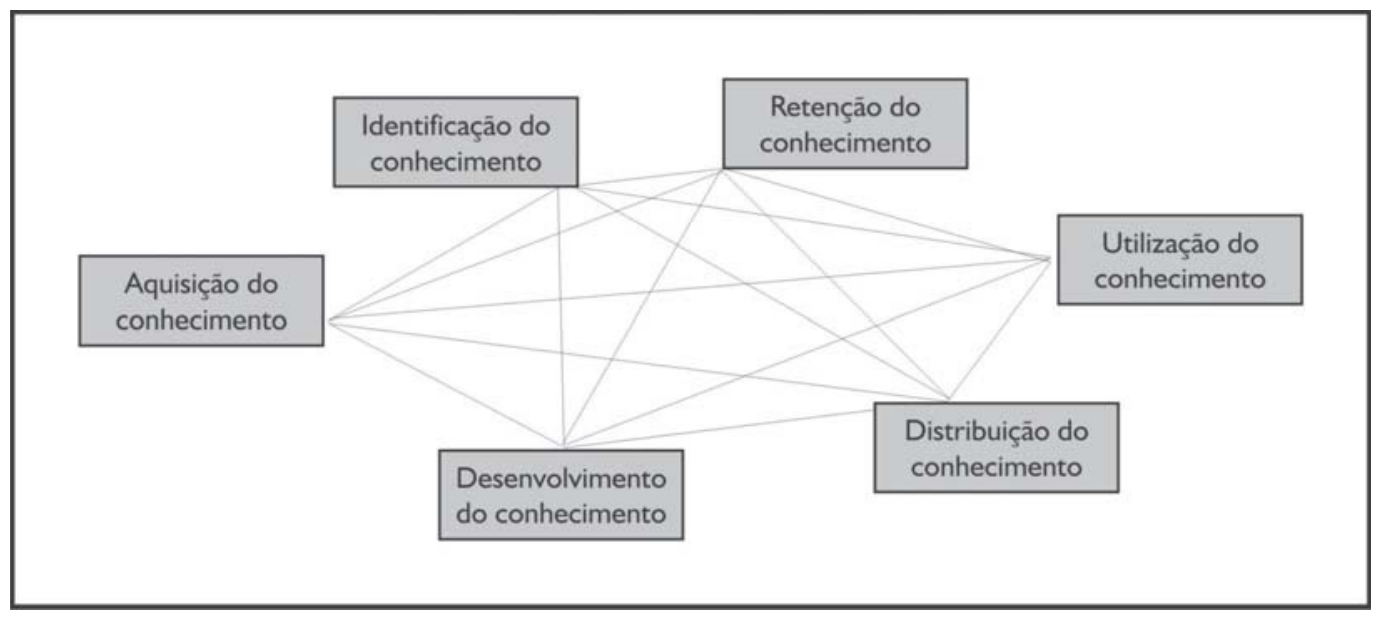

Figura 1: Processos essenciais na gestão do conhecimento.

Fonte: Juliani (2002, p. 40). 
Para atingir uma eficácia completa na gestão do conhecimento é essencial que a organização esteja aberta a uma mudança cultural, de comportamento e em sua estrutura organizacional, através da revisão dos processos listados na Figura 1. As instalações de sistemas modernos para realizar o gerenciamento do conhecimento, por si sós, sem que ocorra a adaptação da empresa nesses processos, não trarão a mudança.

\section{I.I Criação do Conhecimento}

Muitos são os responsáveis pela criação, desenvolvimento e incorporação do conhecimento na organização, sendo que cada colaborador possui seu papel único e específico. $\mathrm{O}$ valor agregado a essas contribuições não deve ser determinado pelo grau hierárquico que ocupa o indivíduo, mas, sim, pela informação que ele está fornecendo.

De acordo com Davenport e Prusak (1998, p. 63), a geração de conhecimento ocorre nas organizações "à medida que interagem com seus ambientes", pois elas absorvem as informações disponibilizadas e transformamnas em conhecimento. Esse conhecimento será agregado às experiências já vivenciadas pela organização, assim como aos seus valores e regras internas.

Na visão de Campos e Barbosa (2001, p. 5)

[...] o que realmente importa é como o conhecimento é adquirido e como nós podemos usar este conhecimento de maneira a alcançar resultados positivos que venham de encontro às necessidades da empresa.

Em complemento Nonaka e Takeuchi (1997, p. 106) comentam que o

[...] conhecimento é perecível, as organizações não podem se tornar complacentes com o conhecimento hoje, já que diferentes tipos de conhecimento serão necessários à medida que ocorrem mudanças no ambiente corporativo.

Segundo Floriano Jr. (2004, p. 28), a geração de conhecimento pode ser identificada como um processo constante de interação entre as diversas dimensões da organização e o seu relacionamento com o ambiente. Dessa forma, pôde-se visualizar que as gerações de conhecimento ocorreram atra- 
vés dos indivíduos (interna) ou por influência do ambiente (externa), as quais serão abordadas a seguir.

\section{I.I.I Geração Interna e Externa de Conhecimento}

A geração interna do conhecimento é aquela pela qual a organização desenvolve as competências e conhecimentos dos indivíduos. Os conhecimentos nas organizações são gerados a partir da integração entre os colaboradores e da troca de experiências, valores e crenças.

O desenvolvimento do conhecimento dentro da organização possui algumas vantagens em relação à sua aquisição de forma externa. A principal vantagem é que o conhecimento tem a tendência de prosperar de forma mais eficaz no ambiente onde foi criado (DAVENPORT; PRUSAK, 1998).

Seguindo caminho inverso aos aspectos de geração interna do conhecimento, na geração externa do conhecimento a organização absorve de fontes externas à empresa os conhecimentos já constituídos e apenas incorporaos. Na visão de Floriano Jr. (2004, p. 28) "a geração externa de conhecimento geralmente é praticado por empresas que não possuem estruturas suficientes para desenvolver conhecimentos importantes internamente". As empresas que optam pela estratégia externa de geração de conhecimento, de forma geral, utilizam fontes encontradas no mercado.

Os conhecimentos externos podem ser assimilados de fontes variadas, tais como: consultores externos, aquisição de outras empresas, stakeholders ou produtos que compreendem conhecimentos (FLORIANO Jr., 2004).

Sendo assim, torna-se primordial que cada empresa avalie os conhecimentos adquiridos de acordo com suas necessidades e com recursos disponíveis, para, então identificar se a compra é a melhor alternativa ou se será melhor investir no desenvolvimento interno de conhecimento.

\subsubsection{Fases do Processo de Criação do Conhecimento}

A seguir, apresentam-se os modelos de criação do conhecimento organizacional, propostos por Nonaka e Takeuchi e Campos e Barbosa, os quais são importantes fontes de informações para um estudo da gestão do conhecimento.

Em seu modelo Nonaka e Takeuchi (1997, p. 96) apresentam uma série de etapas distintas, que estão apresentadas a seguir: 
a) Compartilhamento do conhecimento tácito;

b) Criação de conceitos;

c) Justificação dos conceitos;

d) Construção de um arquétipo; $e$

e) Difusão interativa do conhecimento.

Davenport e Prusak (1998, p. 81) destacam que "o denominador comum de todos esses esforços é a necessidade de se alocarem tempo e espaço apropriados para a criação ou aquisição do conhecimento", podendo esse espaço ser eletrônico, bibliotecas, laboratórios, salas de bate-papo, reuniões, etc.

\subsection{Mapeamento do Conhecimento}

O mapa do conhecimento de qualquer organização informa onde está o conhecimento, seja ele um banco de dados ou pessoas, porém, este não fica armazenado no mapa. Na concepção de Davenport e Prusak (1998, p. 88) "o desenvolvimento de mapas de conhecimento envolve localizar os conhecimentos importantes dentro da organização e depois publicar algum tipo de lista ou quadro que mostre como encontrá-los".

Em complemento, Campos e Barbosa (2001, p. 8) descrevem que

[...] o mapeamento dos ativos intelectuais significa a identificação e localização de conhecimento de um grupo de pessoas sobre um assunto específico. Este mapa é uma representação das habilidades e competências segundo uma visão integrada com o processo de negócios da organização, onde cada funcionário, ou colaborador, tem suas competências mapeadas e classificadas de acordo com o nível de conhecimento do assunto.

Esses mapas podem direcionar a busca do conhecimento em pessoas, em banco de dados ou em documentos, de forma que os colaboradores sabem onde procurar as fontes das informações, quando necessário.

Através da realização do mapeamento torna-se possível à organização identificar quais colaboradores caracterizam-se como os detentores do conhecimento, assim como verificar os indivíduos ou grupos de pessoas que apresentam qualquer deficiência. Sendo assim, pode-se identificar maneiras 
de disseminar o conhecimento e vislumbrar qual a melhor formação de equipes de trabalho para desenvolver novos projetos de uma maneira mais ágil e dinâmica (CAMPOS; BARBOSA, 2001).

Davenport e Prusak (1998, p. 88) acrescentam que:

[...] as informações necessárias para se criar um mapa do conhecimento normalmente já existe nas organizações, porém em forma fragmentada e não-documentada. Cada funcionário tem um pedacinho na cabeça, sabe qual é o seu próprio conhecimento e onde ir para respostas a suas perguntas.

Entretanto, Davenport e Prusak (1998, p. 91) informam que "mapas elaborados a partir do conhecimento de pessoas podem ser complexos, porque as estruturas de conhecimento são complexas", quer dizer, o fator conhecimento é perecível no tempo, pois muda e se desenvolve com o passar dos anos, além de possuir elevado grau de subjetividade.

As organizações que elaboram seus mapas de conhecimento, de forma geral, realizam entrevistas com seus colaboradores visando esclarecer quais os conhecimentos que possuem e qual fonte utilizam quando necessitam de qualquer informação. É dessa forma que a empresa identifica os mapas mentais individuais de cada funcionário. Logo após, com frequência, a empresa analisa as respostas apresentadas pelos colaboradores e elabora um mapa geral a partir dos mapas individuais de cada colaborador (DAVENPORT; PRUSAK, 1998).

\subsection{Compartilhamento do Conhecimento}

Tonet e Paz (2004) definem compartilhamento de conhecimento como sendo "o comportamento do indivíduo de repassar o que sabe as pessoas com quem trabalha e de receber o conhecimento que elas possuem", $e$ ainda afirmam que esse "compartilhamento de conhecimento é um componente chave dos sistemas de gestão do conhecimento".

No atual mercado em que as organizações estão inseridas, o ato de compartilhar o conhecimento tem se mostrado de grande importância, porém de difícil concretização. Pois, para que o compartilhamento das informações obtenha êxito, necessita-se do envolvimento dos componentes (destinatário e receptor) nessa transferência. 
Liana Souza da Rosa - Marcos Baptista Lopes Dalmau - Alessandra de Linhares Jacobsen

O que se espera é que o destinatário ou receptor assimile o conhecimento compartilhado pela fonte ou emissor de forma completa e sem interrupções, embora o conhecimento e habilidades anteriores bem como a motivação dos envolvidos podem causar influencias diretas nesse processo (TONET; PAZ, 2004).

Tonet e Paz (2004) descrevem que

[...] ao compartilhar conhecimento no trabalho, os indivíduos precisam justificar em público as suas crenças, e para isso enfrentam quatro grandes barreiras organizacionais: (1) necessidade de linguagem legítima, que permita explicitar o conhecimento tácito; (2) histórias organizacionais; (3) procedimentos predefinidos; (4) os paradigmas da empresa.

A empresa pode realizar a codificação do conhecimento de diversas formas, por exemplo, através da elaboração de manuais ou de projetos de engenharia. $\mathrm{O}$ ato de codificar as informações possui o objetivo principal de tornar acessível e facilitar a compreensão dos conhecimentos, atingindo assim um número maior de colaboradores atuantes na organização (FLEURY; OLIVEIRA Jr., 2001).

As empresas possuem conhecimentos que já se encontram disseminados e compartilhados por todos os colaboradores da organização, entretanto, existem diversas informações que pertencem a colaboradores específicos ou a equipes de trabalho. O grande desafio das organizações é identificá-las, codificá-las e torná-las acessíveis aos demais colaboradores (FLEURY; OLIVEIRA Jr., 2001).

Grande diferencial competitivo da organização que realiza ações efetivas no compartilhamento das informações é a sua capacidade de aperfeiçoar o processo para obter a reutilização do conhecimento; quer dizer, o conhecimento às vezes fica restrito aos colaboradores de departamentos específicos da organização, enquanto os demais procuram soluções simples para resolução de seus problemas, embora esses problemas possam ser solucionados com o conhecimento já previamente assimilado por algum departamento da organização (TONET; PAZ, 2004).

Para uma disseminação eficaz de conhecimento é primordial a existência de meios de comunicação eficientes na organização, e ainda, que todos 
os colaboradores tenham acesso a esta comunicação de forma eficiente, obedecendo-se de forma lógica os níveis hierárquicos e seu valor estratégico (MELO, 2003).

\subsection{Retenção e Utilização do Conhecimento}

A retenção do conhecimento é um conjunto de processos que engloba a realização de filtragem dos dados disponíveis e o armazenamento da informação para posterior utilização desses conhecimentos. A ação de retenção do conhecimento é subdividido em etapas: (a) filtragem, (b) armazenagem e (c) atualização de informações, para posterior (d) utilização do conhecimento.

A primeira etapa nesse processo de retenção do conhecimento é a realização de filtragem das informações para que sejam armazenadas apenas aquelas com importância à organização, e para que os demais dados, que não possuem representatividade, possam ser descartados. A fase de armazenagem refere-se a etapa em que a organização, em geral com auxílio da tecnologia da informação, guarda as informações para que sejam utilizadas por outros colaboradores quando necessário. Na visão de Juliani (2002, p. 50)

[...] três são os meios de armazenamento: colaboradores individuais (através da manutenção dos especialistas na empresa), grupos (pelo fato de a memória do grupo ser superior àquelas dos indivíduos) e computadores (pela capacidade ilimitada de armazenamento).

Já a etapa de atualização possui o objetivo de manter a qualidade e atualização dos conhecimentos armazenados visando auxiliar no processo de tomada de decisão na organização (JULIANI, 2002).

A utilização do conhecimento é a última etapa dos processos de gestão do conhecimento. Na visão de Floriano Jr. (2004, p. 59) "a utilização do conhecimento representa a efetivação do processo de gestão do conhecimento; quando o conhecimento é posto em prática e agrega valor a empresa".

Segundo Probst, Raub e Romhardt (2002), as características necessárias para tornar um conhecimento favorável à utilização são as simplicidades, as disponibilidades e as compatibilidades com o contexto em que será consultado. 
Entretanto, existem algumas barreiras relacionadas ao uso do conhecimento. Essas barreiras, em sua maioria, estão relacionadas à não adequação da cultura e dos valores organizacionais à nova concepção da utilização do conhecimento. Segundo Floriano Jr. (2004, p. 60) "algumas barreiras são impostas pelos seus usuários, que deixam de utilizar o conhecimento por não confiar ou respeitar a fonte". Em complemento, Davemport e Prusak (1998, p. 123) afirmam que esta resistência dos usuários ocorre devido ao "orgulho, teimosia, falta de tempo, falta de oportunidade e medo de assumir riscos".

Na visão de Probst, Raub e Romhardt (2002), a utilização do conhecimento pode ser vislumbrada como a fase da implementação da gestão do conhecimento, pois é nessa fase que as ações relativas ao conhecimento são efetivamente realizadas e a organização visualiza os resultados efetivos do gerenciamento planejado.

\section{Resultados da Análise do Estudo de Caso}

\subsection{Análise dos Processos de Gestão do Conhecimento no Departamento Comercial}

\section{I.I Análise do Processo de Geração de Conhecimento}

Em decorrência de avaliações das informações expostas no item supracitado em conjunto com o referencial teórico utilizado para embasamento desta pesquisa, verificou-se a existência de um paralelo entre o modelo de processo de criação do apresentado por Nonaka e Takeuchi (1997) e as práticas em uso pela organização pesquisada. Esse comparativo apresenta-se descrito no Quadro 1. 


\begin{tabular}{|c|c|c|c|}
\hline Fase & $\begin{array}{c}\text { Descrição das } \\
\text { Fases }\end{array}$ & Referencial Teórico & Relação Prática \\
\hline 1 & $\begin{array}{c}\text { Compartilhando } \\
\text { Conhecimentos } \\
\text { Tácitos }\end{array}$ & $\begin{array}{l}\text { Esta etapa caracteriza-se pela bus- } \\
\text { ca do compartilhamento do conhe- } \\
\text { cimento tácito de cada indivíduo } \\
\text { da organização. Por tratar-se de in- } \\
\text { divíduos com culturas, conheci- } \\
\text { mento e histórias de vida diferenci- } \\
\text { adas, pode ser descrita como a eta- } \\
\text { pa de maior criticidade na criação } \\
\text { de conhecimentos organizacionais } \\
\text { (NONAKA; TAKEUCHI, 1997). }\end{array}$ & $\begin{array}{l}\text { O compartilhamento de infor- } \\
\text { mações ocorre mediante a re- } \\
\text { alização de reuniões e conver- } \\
\text { sas informais. }\end{array}$ \\
\hline 2 & $\begin{array}{l}\text { Criação de } \\
\text { Conceitos }\end{array}$ & $\begin{array}{l}\text { Esta etapa é responsável pela } \\
\text { conversão com conhecimento tá- } \\
\text { cito já compartilhado em conhe- } \\
\text { cimento explícito (NONAKA; } \\
\text { TAKEUCHI, 1997). }\end{array}$ & $\begin{array}{l}\text { Nessas reuniões, após todos os } \\
\text { participantes terem exposto } \\
\text { suas considerações, realiza-se o } \\
\text { desenvolvimento e transforma- } \\
\text { ção dessas informações em co- } \\
\text { nhecimento. }\end{array}$ \\
\hline 3 & $\begin{array}{c}\text { Justificação de } \\
\text { Conceitos }\end{array}$ & $\begin{array}{l}\text { Após a conversão do conheci- } \\
\text { mento tácito em explícito, os no- } \\
\text { vos conhecimentos precisam ser } \\
\text { justificados pela organização, isto } \\
\text { é, "a justificação envolve o pro- } \\
\text { cesso de determinação de que os } \\
\text { conceitos recém-criados valem re- } \\
\text { almente a pena para a organiza- } \\
\text { ção e a sociedade". Esta avalia- } \\
\text { ção que a organização realiza en- } \\
\text { volve análises de "custos, margem } \\
\text { de lucro e grau de contribuição de } \\
\text { um produto novo para o cresci- } \\
\text { mento da empresa" (NONAKA; } \\
\text { TAKEUCHI, 1997, p. 99). }\end{array}$ & $\begin{array}{l}\text { Nesta etapa ocorre a verifica- } \\
\text { ção dos conhecimentos desen- } \\
\text { volvidos. No caso de tratar-se } \\
\text { apenas de alteração de diretri- } \\
\text { zes ou novos processos, isso é } \\
\text { repassado aos colaboradores. } \\
\text { Porém, caso este novo conhe- } \\
\text { cimento esteja relacionado } \\
\text { com uma nova precificação ou } \\
\text { nova forma de comercialização, } \\
\text { por exemplo, ocorrerá a verifi- } \\
\text { cação financeira mediante aná- } \\
\text { lises de custos, margens de con- } \\
\text { tribuição, taxas internas de re- } \\
\text { torno, etc. }\end{array}$ \\
\hline
\end{tabular}

Quadro 1: Tabela comparativa entre Teoria de Nonaka e Takeuchi e a prática na empresa. Fonte: Elaborado pelos autores. 


\begin{tabular}{|c|c|c|c|}
\hline Fase & $\begin{array}{c}\text { Descrição das } \\
\text { Fases }\end{array}$ & Referencial Teórico & Relação Prática \\
\hline 4 & $\begin{array}{l}\text { Construção de } \\
\text { um Arquétipo }\end{array}$ & $\begin{array}{l}\text { Depois de justificado, esse conhe- } \\
\text { cimento é transformado em algo } \\
\text { tangível ou concreto, ou seja, em } \\
\text { um arquétipo (protótipo) que } \\
\text { pode assumir a forma de um pro- } \\
\text { duto "concreto" ou em um me- } \\
\text { canismo operacional, no caso de } \\
\text { inovações "abstratas" (NONAKA; } \\
\text { TAKEUCHI, 1997). }\end{array}$ & $\begin{array}{l}\text { Esta etapa é responsável pelo } \\
\text { compartilhamento dos conhe- } \\
\text { cimentos desenvolvidos. Esta } \\
\text { ampla informação ocorre me- } \\
\text { diante repasse de e-mails e in- } \\
\text { formativos. Esses informativos } \\
\text { serão melhor descritos no tópi- } \\
\text { co a seguir. }\end{array}$ \\
\hline 5 & $\begin{array}{l}\text { Difusão Interativa } \\
\text { do Conhecimento }\end{array}$ & $\begin{array}{l}\text { Segundo Nonaka e Takeuchi } \\
\text { (1997, p. 101) o processo de cri- } \\
\text { ação de conhecimento "não ter- } \\
\text { mina com a conclusão do arqué- } \\
\text { tipo". Afirmam que o "novo con- } \\
\text { ceito que foi criado, justificado e } \\
\text { transformado em modelo passa } \\
\text { para um novo ciclo de criação de } \\
\text { conhecimento em um nível } \\
\text { ontológico diferenciado". }\end{array}$ & $\begin{array}{l}\text { Após ser amplamente difundi- } \\
\text { do, esse conhecimento acaba } \\
\text { por ser constantemente desen- } \\
\text { volvido em decorrência dos } \\
\text { ajustes e consideraçóes realiza- } \\
\text { das pelos colaboradores. }\end{array}$ \\
\hline
\end{tabular}

Quadro 1: Tabela comparativa entre Teoria de Nonaka e Takeuchi e a prática na empresa. Fonte: Elaborado pelos autores.

Pôde-se concluir que os setores alocados no departamento comercial apresentam características diferenciadas, visto que a forma como esses setores manejam e trabalham a informação não são iguais. Sem olvidar que o setor de planejamento, quando da realização de suas atividades, trabalha exclusivamente com a transformação, em conhecimentos estratégicos, de informações selecionadas e coletadas na Intranet.

Por sua vez, a Gerência de Negócios trabalha com a geração de conhecimentos internos e com os conhecimentos gerados externamente. Isso porque a Gerência de Negócios recebe muitas informações brutas encaminhadas pelos escritórios regionais e demais setores da organização. Essas informações precisam ser trabalhadas e lapidadas para posterior apresentação à Gerência, Diretoria ou Vice-Presidências. Em contra partida, esse setor, para realizar suas atividades, utiliza-se também de conhecimentos já gerados por outros setores da empresa, como, por exemplo, projetos técnicos que são elaborados por um setor de engenharia. 
De forma gradual, pôde-se visualizar que o Suporte Comercial é o setor mais operacional do departamento comercial. Essa operacionalidade é consequência da forma de atuação do setor que, na maioria dos casos, trabalha com os conhecimentos gerados por outros departamentos. Isto é, recebe os projetos e as avaliações prontas e as adapta para emitir suas propostas de preço, gerar contratos ou, até mesmo, realizar a solicitação de produção de equipamentos.

Referente à forma como esses conhecimentos são gerados, verifica-se que grande parte da transformação de informações em conhecimentos ocorre mediante realização de reuniões e através de conversas formais e informais.

\section{I.2 Análise do Processo de Armazenagem de Conhecimento}

Independente da forma como o conhecimento é gerado no departamento, mediante conhecimentos gerados internamente ou por fontes externas, torna-se essencial que eles sejam realmente armazenados para posterior utilização.

Através de análises das informações obtidas com a realização das entrevistas e com as tabelas supracitadas, pôde-se constatar que a armazenagem de informações e conhecimentos não é uma prática difundida entre todos os colaboradores do departamento comercial. Embora 87\% dos colaboradores afirmaram registrar as informações, ainda existem $13 \%$ de colaboradores que não possuem esta preocupação. Dessa forma, pôde-se subentender que aproximadamente $13 \%$ dos conhecimentos que circulam nesse departamento deixam de ser registrados. Embora, em entrevista, alguns superiores afirmam existir diretrizes instituídas no setor para que os conhecimentos e informações sejam armazenados, $30,4 \%$ dos indivíduos alocados no departamento não visualizam qualquer preocupação de seus supervisores referente esses procedimentos.

Referente aos sistemas utilizados para armazenamento de conhecimentos e informações, pôde-se constatar a existência de vários bancos de dados, sendo que cada um apresenta um fim específico. Dessa forma, as informações e conhecimentos são armazenados em pedaços, isto é, cada pedaço é registrado em um banco de dados e, quando se precisa de informações completas, torna-se necessário realizar uma busca e juntar todos os pedaços de forma coerente. Essa diversidade de bancos de dados dificulta a armazena- 
Liana Souza da Rosa - Marcos Baptista Lopes Dalmau - Alessandra de Linhares Jacobsen

gem das informações, sua consulta, seu compartilhamento e sua posterior utilização.

Entretanto, além de existir essa divisão nos sistemas utilizados, pôde-se constatar que os colaboradores não utilizam todos os sistemas como fonte de informação para consulta. Nesse contexto, pôde-se concluir que, como os colaboradores não realizam consulta em todos os bancos de dados disponíveis, parte da informação acaba sendo perdida. Assim, se realizarmos a soma do índice de indivíduos que não armazenam suas informações, com a quantidade de informações disponíveis mas que não são utilizadas, pode-se obter uma faixa considerável de conhecimento que o departamento acaba por não visualizar.

Além dessas considerações, torna-se importante ressaltar que o setor de planejamento trabalha exclusivamente com informações estratégicas, e, por possuir essa característica, é um departamento de essencial importância. Entretanto, apenas parte dos conhecimentos gerados fica armazenada, através de relatórios e apresentações, no microcomputador da supervisora, outra parte somente ela tem conhecimento, pois não está armazenada. A empresa precisa considerar esse fato e realizar ações para que esses conhecimentos e os detalhes das avaliações fiquem registrados.

\subsubsection{Análise do Processo de Compartilhamento de Conhecimento}

Os superiores do departamento comercial utilizam-se do repasse de emails, realização de reuniões e elaboração de informativos para compartilhar os conhecimentos já constituídos com os demais colaboradores. Essas formas de compartilhamentos são válidas, porém, o ideal é que todas essas informações sejam divulgadas e, posteriormente, fiquem armazenadas em um sistema ou banco de dados específico, ou um local onde seja viável a realização de consultas posteriores.

Analisando-se as entrevistas e respostas dos questionários, pôde-se constatar que, embora quase todos os superiores afirmem divulgar todas as informações, essa não é a percepção dos colaboradores. Tal assertiva torna-se válida quando se identifica que $8,7 \%$ dos colaboradores afirmaram que seus supervisores não repassam todos os conhecimentos, e ainda quando 47,8\% declararam não ter certeza desse repasse. Em contra partida, esses colaboradores, em sua maioria, também não realizam o repasse completo de informações: $52,2 \%$ afirmaram compartilhar com os indivíduos pertencentes ao seu 
grupo de trabalho apenas alguns conhecimentos, e 17,4\% não trocaram ideias, conhecimentos e experiências com colaboradores pertencentes aos demais setores da organização. Dessa forma, o departamento comercial acaba por não compartilhar grande parcela do conhecimento que circula diariamente em seu interior.

Referente aos recursos disponibilizados aos colaboradores para a realização de suas atividades e o compartilhamento de seus conhecimentos, identificou-se, através de afirmação dos colaboradores e dos superiores, que os equipamentos de informática utilizados estão desatualizados e que, por isso, prejudicam a velocidade com a qual as tarefas são realizadas. Dessa forma, torna-se essencial que a empresa realize análise dos equipamentos utilizados e realize atualização dos mais desatualizados.

Outro fator que necessita menção é a ausência de treinamentos realizados pelo departamento comercial aos seus colaboradores. Dentre as observações assinaladas, pôde-se concluir que existe a necessidade da realização de treinamentos com foco nas atividades desempenhadas pelos colaboradores, sendo que os treinamentos precisam ser realizados com frequência maior. A empresa realiza alguns treinamentos aos seus colaboradores mediante a realização do Levantamento de Necessidades de Treinamento (LNT), entretanto, o volume de treinamentos realizados com a participação dos colaboradores do departamento comercial é baixo, visto que apenas $13 \%$ dos indivíduos afirmaram que, quando o treinamento é solicitado, sempre é realizado. De todos os colaboradores do departamento comercial, 39,1\% nunca foram convidados a participar da LNT, e 13\% afirmaram que fazem a solicitação dos treinamentos, porém eles nunca foram realizados.

Verificou-se que, quando de sua organização física, o layout do departamento comercial foi especialmente constituído para facilitar a troca de informações e conhecimentos. Essa preocupação pode ser evidenciada mediante a percepção dos colaboradores. Porém, essa mesma formação que torna os colaboradores mais próximos, resultou em reclamações referente ao volume de conversas. Essas conversas, segundo os colaboradores, ocorrem com frequência e prejudicam a concentração e o desenvolvimento das atividades. Tal fato foi evidenciado mediante observação do departamento.

Atualmente, a empresa possui uma característica acentuada de centralização das informações em um dos Vice-Presidentes, sendo que ele é responsável pela definição de estratégias e grandes projetos. Hoje, em decorrência dessa centralização, as informações não são completamente comparti- 
Liana Souza da Rosa - Marcos Baptista Lopes Dalmau - Alessandra de Linhares Jacobsen

lhadas. Entretanto, a empresa está iniciando um processo de mudanças e transformações. Dentre essas mudanças, pôde-se identificar o início de uma preocupação em compartilhar os conhecimentos. Acredita-se ser essa uma tendência que será difundida entre a cúpula estratégica da organização.

\section{I.4 Análise do Processo de Mapeamento de Conhecimento}

O departamento comercial não possui um mapeamento dos conhecimentos e atividades realizadas pelos seus colaboradores. Há um mapa apenas mental, isto é, cada indivíduo, em decorrência de sua experiência no departamento, constrói um mapa mental onde constam as atividades e responsabilidades dos demais funcionários. Por isso, $21,7 \%$ dos colaboradores afirmaram possuir dificuldades em localizar informações pessoas, essa dificuldade é decorrente da falta de formalização.

Torna-se essencial que o departamento possua um documento oficial, onde esteja descrito as atividades realizadas e responsabilidades dos setores $e$ ainda, as atividades desenvolvidas por cada colaborador e suas competências. Esse documento deve ser elaborado para cada setor e, no final do processo, deve possibilitar a construção de um mapa completo de toda a empresa.

\section{Recomendações à Empresa}

Após concluir a descrição da forma como os processos de gestão do conhecimento e realizar as devidas análises, a autora desta pesquisa descreve algumas observações que devem ser avaliadas pelo departamento comercial de empresa do setor de telecomunicaçóes de Santa Catarina, a fim de melhorar os subsídios para os processos de tomada de decisão:

a) Realizar a validação do mapa de conhecimento elaborado nesta pesquisa, para que ele possa ser o ponto de partida da elaboração de manuais e mapas que auxiliem os colaboradores que desempenham suas atividades no departamento comercial, seja para os atualmente contratados, seja para as contratações futuras;

b) Sugere-se a realização de reuniões periódicas para troca de conhecimento, isto é, reuniões semanais nas quais os colaboradores pos- 
Análise dos processos de gestão do conhecimento no departamento comercial de empresa do setor de telecomunicações...

sam conversar com seus colegas de trabalho sobre suas experiências e conhecimentos adquiridos recentemente. Essas reuniões podem ser realizadas com ou sem a presença do supervisor, sendo que, estando presente, fará o papel de moderador da reunião. Como ação posterior, pode-se elaborar uma ata com os principais conceitos e conhecimentos expostos, possibilitando consultas posteriores;

c) Hoje, as informações são armazenadas em banco de dados diversos. Tem-se a Intranet, Sistema de Força de Venda, Servidor e, ain$\mathrm{da}$, os bancos de dados próprios desenvolvidos em Access (programa de gerenciamento de dados). Considerando que cada banco de dados tem uma finalidade específica, essa diversidade pode causar problemas na busca ou no armazenamento de informações. Dessa forma, o ideal é realizar a incorporação desses sistemas em uma forma única de entrada de dados e uma fonte única de pesquisa, facilitando o registro e a busca posterior de informações;

d) Visando reduzir o ruído proporcionado pela troca de informações entre os colaboradores, pode-se desenvolver um ambiente na Intranet para realizar esse ato. Trata-se de uma sala web onde os colaboradores podem registrar informações, trocar ideias através de um ambiente similar ao chat, e, ainda, seria o local onde todos os informativos ficariam armazenados e disponíveis para consulta;

e) Realizar treinamentos focados nas atividades desenvolvidas pelos colaboradores do departamento comercial com frequência, para fins de reciclagem. Esses treinamentos podem conter formas de melhorar as rotinas operacionais, gerar novos conhecimentos ou, ainda, compartilhar novos conhecimentos e informações;

f) Sugere-se que a empresa avalie a forma como está sendo realizada a LNT. Da forma como está configurada, não apresenta resultados efetivos.

g) Como última sugestão, o departamento comercial precisa iniciar a avaliação para identificar novas formas de armazenar conhecimentos estratégicos, em especial os conhecimentos desenvolvidos pelo setor de planejamento. Esses conhecimentos, hoje, estão armazenados apenas na cabeça da supervisora, e, caso ela se ausente da 
empresa, as atividades ficarão em stand by até que outra pessoa incorpore todas as informações e o feelling do setor, o que, certamente, precisará de um longo tempo.

Embora todas as sugestões apresentadas resultem em contribuições aos processos de gestão do conhecimento desempenhados pelo Departamento Comercial, sabe-se que todas as organizações possuem limitações, seja referente a recursos financeiros seja quanto a processos burocráticos. Por esse motivo, elencou-se as ações recomendadas segundo seu grau de criticidade. Neste primeiro momento, torna-se necessário a realização de três ações simultâneas: a validação do mapa de conhecimento, a unificação do banco de dados e a criação da sala web.

A validação do mapa de conhecimento torna-se de fundamental importância, visto que auxiliará novos colaboradores do departamento comercial a localizar informações e conhecimentos específicos dentro de seus setores. Hoje, as informações e conhecimentos são armazenados em pedaços, isto é, cada pedaço é registrado em um banco de dados e, quando se precisa de informações completas, torna-se necessário realizar uma busca e juntar todos os pedaços de forma coerente. Essa diversidade de bancos de dados dificulta a armazenagem das informações, sua consulta, seu compartilhamento e sua posterior utilização. A simultaneidade da validação dos mapas e do desenvolvimento de algumas ferramentas deve-se ao fato de que, segundo o coordenador de suporte comercial, o setor de desenvolvimento da empresa avaliada possui uma séria de atribuições e projetos em desenvolvimento e um número reduzido de colaboradores desempenhando estas funções. Em decorrência disso, é aceitável o fato de que esses projetos terão um longo período de desenvolvimento, de modo que quanto antes sejam apresentados ao setor de desenvolvimento, o mais breve possível o departamento terá a conclusão. São eles: a unificação dos bancos de dados do departamento e ainda, a criação da sala web.

Logo após a validação do mapa, é de essencial importância que a organização idealize formas, métodos e procedimentos para armazenagem dos conhecimentos estratégicos do Departamento Comercial. Hoje, sabe-se que uma série de conhecimentos estratégicos diversos são gerados diariamente pelo setor de planejamento, e, por tratar-se de fatos estratégicos, acabam não sendo armazenados. Em decorrência desse conhecimento não ser armazenado em sistemas de informação, acaba sendo armazenado na cabeça da 
supervisora (forma de formação de preço, estabelecimento de metas, por exemplo). Isso que é um risco para a organização, pois, em um eventual afastamento, seja ele temporário ou definitivo dessa supervisora, o conhecimento desenvolvido poderá ser perdido.

O banco de dados disponível para o setor de planejamento contempla apenas informações básicas; todo o conhecimento é gerado partindo dessas informações e da experiência daquela profissional; no caso de afastamento, será necessário que outra pessoa assuma as atividades dela; até que essa pessoa assimile e incorpore os principais conceitos e alinhe-se aos objetivos e estratégias das organizações, irá decorrer algum tempo. Isso poderá tornar a organização órfã de conhecimentos, o que resultará em dificuldade no processo de tomada de decisão estratégica do Departamento Comercial e em toda organização.

Ainda assim, é necessário que a organização realize treinamento com todos os colaboradores do Departamento Comercial, deixando clara a importância de tratar com seriedade os conhecimentos desenvolvidos internamente ou fora da empresa. Após agregar o fator importância ao conhecimento, torna-se essencial que os colaboradores igualmente preocupem-se com os processos relacionados ao conhecimento (geração, armazenagem, compartilhamento e mapeamento). Somente após os colaboradores incorporarem a consciência de que é primordial para a organização armazenar todos os conhecimentos e da mesma forma compartilha-los, ocorrerá a redução do volume de informações e de conhecimentos que são perdidos no decorrer de todo o processo, tornando, dessa forma, as informações e conhecimentos completos, seguros e confiáveis. Isso facilitará e tornará mais seguro o processo de tomada de decisão.

É essencial que a organização, como último estágio do processo da melhoria apresentado nesta pesquisa, reavalie o seu planejamento da LNT Levantamento de Necessidades de Treinamento. A LNT é uma grande aliada dos treinamentos descritos no parágrafo anterior, pois objetiva o desenvolvimento pessoal e profissional dos colaboradores. É essencial que a organização consiga apresentar a LNT como um processo confiável e participativo. Conforme exposto nesta pesquisa, os colaboradores demonstraram que, embora solicitem, os treinamentos não são realizados. Esse fato acaba por resultar em falta de credibilidade do projeto. Por isso, é necessário rever os treinamentos que estão sendo ofertados, principalmente quanto a sua viabilidade de concretização. Após essa avaliação, é necessário englobar todos os 
Liana Souza da Rosa - Marcos Baptista Lopes Dalmau - Alessandra de Linhares Jacobsen

colaboradores da organização na definição das prioridades e dos treinamentos necessários, desde que exista o contra interesse dos indivíduos.

\section{Conclusão}

Esta pesquisa pretendeu mostrar a realidade dos processos de gestão dos conhecimentos do departamento comercial de empresa do setor de telecomunicações de Santa Catarina. O objetivo geral foi verificar quais as ações voltadas à gestão do conhecimento deverão ser desenvolvidas para o Departamento Comercial da empresa analisada, para proporcionar novos subsídios ao desenvolvimento de suas atividades. A escolha desse tema deve-se ao fato de que assuntos relacionados à gestão do conhecimento estão sendo, cada vez mais, relatados academicamente e visualizados na prática através de empresas que possuem foco em atividades voltadas para o conhecimento, como é o caso da empresa do setor de telecomunicações de Santa Catarina analisada.

Os objetivos descritos neste trabalho foram desenvolvidos com sucesso. Mediante a realização da fundamentação teórica tornou-se possível desenvolver os conhecimentos, buscando, assim, o embasamento necessário para a realização da pesquisa.

O primeiro objetivo foi identificar os conhecimentos utilizados para o desenvolvimento das atividades do departamento comercial. Para atendimento desse objetivo, realizou-se aplicação de questionários aos colaboradores do departamento comercial, os quais responderam com a descrição das atividades realizadas e as classificaram quanto ao tipo de conhecimento necessário. Após análise das entrevistas e questionários, identificou-se que não existe qualquer mapeamento oficial disponível na organização. A única forma de mapeamento existente é o modelo mental, o qual os superiores e colaboradores procuram seguir.

Outro objetivo foi verificar quais ações são realizadas hoje pelo Departamento Comercial, relacionadas aos processos de gestão do conhecimento. Analisou-se os processos de geração, armazenagem, compartilhamento $e$ mapeamento de conhecimentos, que influenciam a forma como os conhecimentos circulam no departamento.

Ainda, intentou-se analisar as ações realizadas pelo Departamento Comercial relacionadas aos processos de gestão do conhecimento. Nesse obje- 
tivo, verificou-se que os conhecimentos do departamento comercial são gerados de formas diferenciadas nos diversos setores: alguns desenvolvem processo e forma internos de geração de conhecimento de conhecimento; outros utilizam os conhecimentos já desenvolvidos pelos demais departamentos da empresa.

Quanto aos processos de armazenagem, identificou-se a existência de bancos de informações variados, o que pode resultar em problemas para armazenar ou recuperar as informações. Ainda assim, identificou-se que alguns colaboradores assinalam não possuir preocupação em armazenar conhecimentos, o que pode resultar em perda de informações. Referente ao compartilhamento, pôde-se concluir que existe um compartilhamento eficiente, porém, existem algumas ações corretivas necessárias. E, ainda, pôde-se concluir que a empresa não possui mapas oficiais onde estejam descritas as atividades realizadas pelo setor e pelos indivíduos específicos.

Realizou-se a proposição de ações corretivas aos processos de gestão do conhecimento. Foram descritas várias ações que visam fornecer subsídios para a organização aprimorar seus processos de gestão de conhecimento $e$ tomada de decisão, tornando-os mais eficientes.

Por fim, esta pesquisa tornou-se de grande importância para o desenvolvimento acadêmico e profissional, visto que desenvolve novos conhecimentos referentes ao assunto em tela, e, ainda, pela possibilidade de continuidade e posterior implantação das recomendações destacadas neste trabalho acadêmico.

\title{
Analysis of processes knowlodge management in a commercial department of a telecommunication's company in Santa Catarina
}

\begin{abstract}
The main objective of this paper is analyze the processes of knowledge management application in the commercial department of telecommunications company in the sector of Santa Catarina. Starting from this perspective, it had study the theories related to the processes of knowledge management, as it pertains to generation, sharing, storage and mapping of knowledge. Concerning to a methodology, it has developed a quantitative study, qualitative, descriptive and case study. The primary
\end{abstract}


data were obtained through of questionnaires applied to employees of the commercial department and semi-structured interviews conducted with commercial director, manager, coordinator and Supervisory and the data side through bibliographic survey. It was identified that the processes of generating knowledge is different in each sector of the department, the processes of these stocks are not fully effective because not all knowledge is registered by employees. The sharing of knowledge is achieved by holding meetings, emails and informative, but not all knowledge is shared between employees of the same group and with other employees of the company. While it is important to emphasize that there is no formal mapping of knowledge and skills of individuals, their tasks and responsibilities.

Key-words: Knowledge Management. Information. Telecommunication.

\section{REFERÊNCIAS}

ANGELONI, M. T. Modelo integrado de decisão para as organizações. Revista Ciências da Informação. Instituto Brasileiro de Informação em Ciência e Tecnologia, v. 32, n. I, 2003.

BUENO, G. S. et al. Gestão estratégica do conhecimento. Revista da FAE, Curitiba, v. 7, n. 1, p. 99-102, jan./jun. 2004. Disponível em: <www.unifae.br/ publicacoes/pdf/revista_da_fae/fae_v7_n1/rev_fae_v7_n1_07_giovatan.pdf > Acesso em: 21 maio 2007.

CAMPOS, R. L.; BARBOSA, F. V. Gestão do conhecimento: o conhecimento como fonte de vantagem competitiva sustentável. In: ENCONTRO DA ANPAD. 25., 2001. Campinas (SP). Anais... Campinas, 2001.

DAVENPORT, T. H.; PRUSAK, L. Conhecimento empresarial. São Paulo: Campus, 1998.

FLEURY, M. T. L.; OLIVEIRA Jr., M. M.; FLEURY, A. Gestão estratégica do conhecimento: integrando aprendizagem, conhecimento e competências. São Paulo: Atlas, 2001.

FLORIANO Jr., P. R. Gestão do conhecimento em comunidades de prática: estudo de caso na comunidade da construção da grande Florianópolis. 2004. 163f. Trabalho de Conclusão de Estágio (Graduação em Administração) - Curso de Administração, Universidade Federal de Santa Catarina.

Florianópolis, 2004. 
Análise dos processos de gestão do conhecimento no departamento comercial de empresa do setor de telecomunicações...

JULIANI, J. P. Gestão inteligente do conhecimento. Dissertação (Mestrado) - Programa de Pós-Graduação em Engenharia de Produção Universidade Federal de Santa Catarina. Florianópolis, 2002. 118 f. Disponível em: <http://www.tede.ufsc.br/teses/PEPS3676.pdf> . Acesso em: 24 ago. 2007.

MELO, L. E. V. Gestão do conhecimento: conceitos e aplicações. São Paulo: Érica, 2003.

NONAKA, I.; TAKEUCHI, H. Criação de conhecimento na empresa: como as empresas japonesas geram a dinâmica da inovação. Rio de Janeiro: Campus, 1997.

PROBST, G.; RAUB, S.; ROMHARDT, K. Gestão do conhecimento: os elementos construtivos do sucesso. Porto Alegre: Bookman, 2002.

ROSENBERG, M. J. e-LEARNING. São Paulo: Pearson Education do Brasil, 2002.

TONET, H. C.; PAZ, M. G. T. Um modelo para o compartilhamento de conhecimento no trabalho. In: ENCONTRO DA ANPAD, 28, 2004. Curitiba. Anais... Curitiba, 2004. 